\title{
MANAJEMEN PENDIDIKAN DALAM KONSTELASI PROGRESIVISME (TELAAH FILSAFAT PENDIDIKAN JOHN DEWEY)
}

\author{
Ucup Supriatna ${ }^{1}$ \\ ${ }^{1}$ STAI Al-Haudi Ketapang, Kalimantan Barat \\ *Corresponding email: kangucuptea@gmail.com
}

Naskah diterima: 3 Juli 2021| Disetujui: 2 Agustus2021 | Diterbitkan: 19 Agustus 2021

\begin{abstract}
This study aims to generalize the education management system in the constellation of John Dewey's philosophy of progressivism. This research was conducted using library research. Research data obtained through primary and secondary literature on the philosophy of progressivism John Dewey. Researchers document the educational thinking of John Dewey's progressivism, then describe it methodologically. Data analysis was carried out by data reduction, data presentation, and data analysis. The researcher reduces John Dewey's educational thought of progressivism, presents it systematically, then analyzes this thought in the education management system. The results showed; First, humans as educational human resources must be given roles and tasks according to their talents and interests. Humans are agents of change in education. Second, education has a forward and progressive orientation. This is a form of criticism of the scholastic education management system. Progressive education can be realized through a progressive curriculum reconstruction. Third, school educational institutions are miniatures of life in society. Therefore, schools need to be in symbiosis with the community in order to realize educational goals. Fourth, humans who learn have academic freedom. In the sense that humans can learn whatever they want to develop their potential and skills.
\end{abstract}

Keywords: Progressivism; John Dewey; Education

Abstrak: Penelitian ini bertujuan menggeneralisasi sistem manajemen pendidikan dalam konstelasi filsafat progresivisme John Dewey. Penelitian ini dilakukan dengan studi pustaka (library research). Data penelitian diperoleh melalui literatur primer dan sekunder tentang filsafat progresivisme John Dewey. Peneliti melakukan dokumentasi, kemudian mendeskripsikan secara metodologis. Analisis data dilakukan dengan reduksi data, penyajian data, dan analisis data. Peneliti mereduksi pemikiran pendidikan progresivisme John Dewey, menyajikannya secara sistematis, kemudian menganalisis pemikiran tersebut dalam sistemasi manajemen pendidikan. Hasil penelitian menunjukkan; Pertama, manusia sebagai SDM pendidikan harus diberi peran dan tugas sesuai bakat dan minat yang digelutinya. Manusia adalah agent of change dalam pendidikan. Kedua, pendidikan memiliki orientasi ke depan dan progresif. Hal ini sebagai bentuk kritik atas sistem manajemen pendidikan skolastik. Pendidikan progresif dapat terwujud melalui rekonstruksi kurikulum yang progresif. Ketiga, lembaga pendidikan sekolah adalah miniatur kehidupan di masyarakat. Maka dengan itu sekolah perlu bersimbiosis dengan masyarakat guna mewujudkan tujuan pendidikan. Keempat, manusia yang belajar memiliki kebebasan akademik. Dalam arti manusia dapat belajar apapun sesuai yang diinginkan guna mengembangkan potensi dan keterampilan diri.

Kata kunci: Progresivisme, John Dewey, Pendidikan 


\section{PENDAHULUAN}

Mengelola pendidikan agar memiliki kualitas dan layanan pendidikan yang prima merupakan tujuan yang ingin dicapai dalam satuan pendidikan. Misi tersebut mendorong seluruh elemen terutama sumber daya manusia untuk berpartisipasi aktif dalam melakukan hal-hal rekonstruktif guna kemajuan pendidikan. Kemajuan pendidikan atau dengan istilah lain progresivisme pendidikan ialah upaya positif untuk membangun pendidikan ke arah lebih maju, memiliki manfaat, martabat, dan berguna untuk alam semesta. Progresivisme pendidikan mementingkan langkah-langkah rekonstruktif untuk membangun pendidikan ke depan, menjadikan pendidikan sebagai nilai esensial kehidupan manusia, menciptakan daya kreasi akuratif untuk keperluan pragmatis, serta menjunjung tinggi etika pendidikan dalam kehidupan sehari-hari.

Progresivisme pendidikan dapat dilakukan dengan metode manajemen pendidikan. Melalui metode tersebut tujuan pendidikan dapat diwujudkan sedemikian rupa sesuai dengan goals pendidikan yang dirumuskan sebelumnya. Manajemen pendidikan ialah proses kegiatan yang dilakukan bersama terutama di bidang pendidikan dengan memanfaatkan fasilitas-fasilitas yang disedikan. Fasilitas tersebut dapat berupa sumber daya manusia, material, maupun spiritual guna mencapai tujuan pendidikan yang dirumuskan (Gunawan \& Benty, 2017). Sedangkan manajemen pendidikan menurut (Mulyasa, 2004) ialah sebuah proses pengembangan kerjasama antar kelompok guna mencapai tujuan pendidikan yang dirumuskan. Proses pengembangan kerjasama tersebut tidak lepas dari perencanaan, organisasi, aksi, kontrol, dan evaluasi.

Sistem manajemen pendidikan sebagaimana dijelaskan di atas tentu dibentuk dengan paradigma filosofis yang mengatur hubungan antar variabel hingga membentuk sebuah premis ideologis yang kemudian dijadikan asas atas hakikat organisasi pendidikan. Paradigma filosofis yang sekiranya dapat ditinjau ialah paradigma progresivisme. Paradigma tersebut merupakan buah pemikiran dari filsafat pendidikan aliran progresivisme. Filsafat pendidikan progresivisme sebagaimana dikutip (Musyarapah, 2017) dinilai sebagai instrumentalisme, eksperimentalisme, dan environmentalisme yang berkaitan erat dengan alat, lingkungan, pengalaman, kemajuan, dan manfaat daripada perilaku aktivitas yang dilakukan yang dalam hal ini ialah aktivitas pendidikan. Filsafat pendidikan progresivisme memiliki cakupan yang luas baik dari sisi peserta didik, kurikulum, organisasi, dan ilmu pengetahuan (Howlett, 2013). Kunci sistem manajemen pendidikan ialah organisasi yang dapat mengatur tata kelola pendidikan sesuai dengan sistemasi yang ditentukan.

Didapati penelitian-penelitian mutakhir terlkait relevansi manajemen pendidikan dalam tilikan progresivisme. Pertama, penelitian (Islam, n.d.) menyebut aliran progesivisme sangat menghargai kebebasan dan kreatifitas yang dimiliki manajer pendidikan. Menurutnya, seorang manajer harus 
bertumbuh dan berkembang meningkatkan kompetensi yang dimilikinya karena gesekan pengalaman, intelektual, dan moral yang dihadapi secara konsisten. (Islam, n.d.) menempatkan pengalaman (experience) sebagai salah satu bagian dari pendidikan. Setiap hal-ihwal pendidikan yang dilakukan seorang atau manajer pendidikan akan menentukan masa depan pendidikan. Kedua, penelitian (Sirojudin \& Ashoumi, 2020) yang lebih spesifik mengulas aksiologi ilmu pengetahuan dalam tilikan manajemen pendidikan Islam. Penelitian ini menyebut nilai-nilai ekspektasi ilmu pengetahuan dalam manajemen pendidikan Islam tidak lepas dari nilai kepemimpinan yang mampu mengendalikan organisasi dan manajerial yang paripurna ke dalam jiwa seorang manajer pendidikan. Nilai kreatif ialah keniscayaan yang harus dimiliki seorang manajer pendidikan guna menciptakan kreatifitas dan inovasi organisasi. Ketiga, penelitian (Faiz \& Kurniawaty, 2020) yang lebih matang membahas manajemen kurikulum pendidikan merdeka belajar yang dicanangkan oleh Kemendikbud RI dalam paruh tahun 2020/2021. Menurutnya, sistem pendidikan Indonesia yang dicanangkan Mendikbud Nadiem Makarim demikian selaras dengan perspektif filsafat progresivisme John Dewey. Beliau memberikan pandangan bahwa manusia dan pendidikan harus senantiasa mengikuti perkembangan zaman yang mutakhir. Dua aspek yang dinilai penting untuk diikuti di zaman mutakhir ialah aspek keterampilan (skill) dan performance karakter. Pengembangan karakter menjadi hal yang penting guna menyeimbangkan pola akademik dan spiritual manusia. Di sisi lain pendidikan harus dapat menjadi media pengembangan pemikiran kritis manusia, terciptanya kreativitas yang dinamis untuk menemukan hal-hal baru dan bermanfaat untuk kemajuan pendidikan. Keempat, penelitian (Atabik et al., 2019) yang menggunakan landasan filsafat progresivisme sebagai landasan aktualisasi etika, perilaku, dan norma pendidikan. Hasil penelitian ini menyebutkan bahwa implementasi pendidikan karakter di sekolah yang berada di kawasan pondok pesantren selaras dengan konsep mix management. Dalam arti lebih luas ialah sekolah atau lembaga pendidikan yang berada di lingkungan pesantren kebanyakan tengah menggunakan manajemen modern berbasis POAC yang disesuaikan dengan manajemen pesantren yang sentralistik. Perihal ini yang dapat mempengaruhi attitude dan perilaku siswa sebagai buah manajemen lembaga pendidikan yang dikatakan konvergerensi.

Kelima penelitian di atas merupakan eksplorasi akademik atas studi manajemen pendidikan dalam tilikan filsafat pendidikan aliran progresivisme. Penelitian pertama menyebut pentingnya seorang manajer pendidikan dalam mengembangkan kompetensi kognitif, psikomotorik, dan afektif dalam mengelola pendidikan. Semua perilaku terkait pendidikan berbasis tiga kompetensi tersebut akan menentukan nasib pendidikan yang ia pegang. Sementara penelitian kedua mengeksplorasi aksiologi ilmu pengetahuan yang dapat diserap dalam dunia manajemen pendidikan Islam. Penelitian tersebut menyebut seorang manajer pendidikan harus memiliki ruh kepemimpinan yang profesional dan kreatif dalam mengelola satuan pendidikan Islam. Hasil penelitian kedua tersebut memiliki 
kesamaan dengan penelitian pertama, bahwasanya seorang manajer pendidikan harus senantiasa memiliki kompetensi yang unggul, profesional, dan kreativitas guna mengembangkan lembaga pendidikan. Adapun penelitian ketiga menyebutkan bahwa kebijakan manajemen kurikulum pendidikan "Merdeka Belajar" yang dicanangkan oleh Kemendikbud Nadiem Makarim melalui Kemendikbud RI selaras dengan perpektif filsafat progresivisme John Dewey. Menurutunya output dari kebijakan pendidikan ialah melahirkan peserta didik/siswa yang memiliki keterampilan (skill) dan performa karakter yang selaras dengan perkembangan zaman. Sedangkan penelitian keempat memiliki orientasi manajemen lembaga pendidikan yang mengadopsi filsafat progresivisme. Menurutnya, etika, perilaku, dan norma dari peserta didik/siswa yang mengenyam pendidikan menengah dengan menggunakan model manajemen POAC akan berdampak pada sikap peserta didik.

Dari kelima penelitian tersebut secara garis besar mengulas filsafat progresivisme sebagai landasan pendidikan, namun belum mengarah pada orientasi manajemen pendidikan, terlebih progresivisme John Dewey. John Dewey sebagai filosof kontemporer tengah memberikan gagasan hakikat filsafat pendidikan yang beraliran progresivisme. Kemudian bagaimana orientasinya dalam mengorganisasi sistem manajemen pendidikan. Pentingnya landasan filsafat pendidikan progresivisme John Dewey dalam orientasi manajemen pendidikan ialah menunjukkan bahwa manusia sebagai pelaku pendidikan memiliki peran sentral dalam mengelola pendidikan. Guna mendukung tercapainya tujuan pendidikan tersebut manusia dapat bekerjasama dengan sekelompok tertentu dan memanfaatkan fasilitas yang tersedia. Filsafat progresivisme yang digagas John Dewey ini dinilai sangat relevan dengan sistem manajemen pendidikan modern, terlebih jika dibenturkan dengan perkembangan ilmu pengetahuan dan teknologi. Progresivisme John Dewey memandang aktivitas pendidikan akan lebih sempurna dengan memanfaatkan pengalaman, lingkungan, dan alat pendidikan yang tersedia.

Signifikansi penelitian di atas membuahkan tujuan penelitiaan yaitu mendeskripsikan sistem manajemen pendidikan dalam perspektif filsafat progresivisme John Dewey. Sehingga penelitian ini dinilai penting dan memiliki manfaat teoritis dan praktis. Dari sisi teoritis penelitian ini dapat mengeksplorasi paradigma progresivisme dalam dunia pendidikan terlebih manejemen pendidikan. Sistem manajemen pendidikan seharusnya tidak selalu menggunakan paradigma klasik-skolastik. Sistem manajemen pendidikan harus lebih kreatif, maju, dan visoner dalam menghadapi tantangan zaman. Kemudian dalam sisi praktis, penelitian ini dapat dijadikan landasan oleh setiap pengelola pendidikan dalam melakukan organisasi pendidikan. Dengan berlandas pogresivisme, pengelola pendidikan dapat melakukan organisasi pendidikan dengan tata kelola yang lebih profesional, memanfaatkan SDM, materi, dan lingkungan yang tersedia guna mewujudkan pendidikan yang lebih baik. 


\section{METODE}

Penelitian ini menggunakan metode kualitatif yang bersisfat kepustakaan (library research). Sebagai penelitian kepustkaan, data primer penelitian berupa pemikiran filsafat progresivisme John Dewey dalam karya primernya "Democracy and Education". Data sekunder berupa studi kepustakaan pemikiran progresivisme John Dewey yang ditulis dalam e-journal. Teknik pengumpulan data penelitian ialah dokumentasi. Peneliti melakukan dokumentasi atas pemikiranpemikiran progresivisme pendidikan menurut John Dewey dalam berbagai literatur kemudian disajikan secara deskriptif. Analisis data dilakukan dengan mengidentifikasi data, klasifikasi data, penyajian data, dan analisis data. Pada tahap ini peneliti melakukan identifikasi pemikiran-pemikiran progresivisme pendidikan John Dewey dari berbagai literatur, kemudian dari hasil identifikasi peneliti melakukan klasifikasi pada pemikiran tersebut secara dialogis. Langkah selanjutnya adalah penyajian data. Peneliti menyajikan secara sistematis pemikiran-pemikiran progresivisme pendidikan John Dewey dan dilakukan analisis untuk konsep manajemen pendidikan.

\section{HASIL DAN PEMBAHASAN}

\section{John Dewey dan Progresivisme Pendidikan}

\section{Biografi Singkat}

John Dewey ialah seorang filosof kontemporer yang beraliran pragmatisme. Selain sebagai seoranag folosof, ia juga getol memperhatikan perubahan sosial. Perhatiannya dialihkan dalam studi kritik sosial. Tidak selesai sampai di sana, John Dewey juga menaruh perhatian pemikirannya untuk bidang pendidikan (Audi, 2015). Beliau dilahirkan tahun 1859 di Burlington. Ia menyelesaikan pendidikan di Baltimore dan menjadi profesor dalam bidang filsafat dan pendidikan di beberapa universitas. John Dewey dikenal sangat produktif dalam menulis. Tidak kurang dari 40 karya buku dan 700 artikel telah rampung ditulisnya. Tulisannya banyak yang menyinggung filsafat, studi sosial, dan pendidikan (Wikipedia, 2021). John Dewey sangat mempengaruhi pola pemikiran masyarakat Amerika Serikat pada pertengahan abad XX. Ia sering memberikan kuliah filsafat khas Amerika dan pragmatisme bersama filosof terkenal Charles S. Peierce, dan William James. Seorang pemikir pendidikan progresif (Wulandari, 2020).

John Dewey berpendapat dalam karya My Pedagogic Creed, bahwasanya pendidikan adalah bagian dari kehidupan dan bukanlah unsur untuk mempersiapkan hidup. Ia menekankan sekolah harus selaras dengan kebutuhan dan konteks masyarakat. Hal ini diungkap dalam School and Society. Dalam How We Think, ia mengajarkan cara-cara berpikir progresif untuk manusia. Lebih lanjut dalam Democracy and Education, Dewey menjelaskan hakikat pendidikan yang demokratif. Kemudian 
dalam Experience and Education, ia menggeneralisasi bahwa pendidikan harus dinisbatkan dengan pengalaman. Ia juga menegaskan bahwa pendidikan ialah kebutuhan sehari-hari yang dipersiapkan untuk kehidupan masa mendatang (Mualifah, 2016).

Dalam mengekspresikan pemikiran dalam dunia pendidikan, John Dewey mendirikan laboratorium sekolah (Laboratory Scholl) dengan nama “The Dewey School”. Lembaga yang dirikan olehnya berfungsi untuk menguji teori-teori pendidikan yang ia cetuskan. John Dewey dalam memandang pendidikan, salah satunya seorang harus meninggalkan tradisi menghafal dan mengedepankan tradisi menalar. Karena dengan menalar, seorang dapat mengukur seberapa jauh potensi akal. Seorang dapat berdiskusi dan dan mengembangkan kreativitas secara mandiri maupun kelompok. Selain itu John Dewey juga memberikan inspirasi kepada orang-orang yang mau meneruskan perjuangannya dalam bidang pendidikan di Chicago (Ruslan, 2018).

\section{Progresivisme Pendidikan}

Diskurusus progresivisme merupakan hal baru di barat. Progresivisme dalam bidang pendidikan merupakan embrio dari gerakan reformasi sosio-politik yang memiliki cakupan luas terutama di Amerika Serikat pada abad XIX dan XX. Hal ini sebagai dampak industrialisasi masif yang terjadi di AS. Progresivisme dalam bidang politik dipelopori R.L Follete dan W. Wilson dengan pandangannya demokrasi politik. Sementara progresivisme dalam bidang sosial dipelopori oleh James Adams dengan mengadakan gerakan meningkatkan kesejahteraan masyarakat (Ruslan, 2018).

Progresivisme dalam bidang pendidikan hadir sebagai bentuk kritik eksternal atas sistem pendidikan tradisional-skolastik. Progresivisme pendidikan menyebut tindak daripada sistem pendidikan tradisional yang mengedepankan metode mendengar dan menghafal sudah tidak relevan dengan sistem pendidikan modern. Karena sifatnya yang tidak mengasah kemampuan akal untuk berpikir secara kritis dan logis (Knight, 1998). Progresivisme pendidikan hakikatnya adalah mengasah kemampuan dasar fundamental secara intelektual maupun emosional untuk menuju tabiat manusia yang lebih baik (Dewey, 1997a). Pendidikan menurut ialah penataan ulang atau rekonstruksi untuk hal yang lebih maju. Konsep pendidikan ini selaras dengan filsafat pendidikan. Rekonstruksi pendidikan menurut John Dewey sebagaimana dikutip (Arifin, 2021) adalah mengatur sistem dan manajerial pendidikan sedemikian rupa untuk menuju pendidikan yang lebih baik, cakap, dan inovatif.

Progresivisme pendidikan didefinisikan sebagai aliran filsafat yang memiliki orientasi pendidikan lebih progresif. Manusia merupakan subjek pendidikan yang memiliki peran penting untuk melakukan hal yang lebih maju dan progresif karena memiliki bekal kompetensi. Dengan 
kompetensi yang dimilikinya, manusia dapat menyelesaikan masalah dengan sendirinya (Dewey, 1997a). John Dewey memberikan gambaran bahwa sekolah merupakan miniatur masyarakat. Dalam arti setiap peserta didik yang belajar di sekolah, maka akan dipersiapkan untuk hidup di masyarakat. Sekolah dan masyarakat seharusnya dapat berinteraksi guna membentuk karakter peserta didik yang lebih peka dalam memandang fenomena sosial dan tidak terlibat dalam hal akademik (Wulandari, 2020). Sebagaimana manusia menjalin interaksi sosial dengan seksama. Maka melalui jalur interaksi sosial dan pengalaman, manusia dapat mengembangkan potensi akal yang dimiliki. Pengalamanpengalaman empiris ini kemudian dikonstruksi dalam satuan pendidikan (Dewey et al., 2008).

Manusia sebagai subjek pendidikan memiliki kebebasan untuk berekspresi. Dalam situasi belajar, manusia bebas menentukan apa yang akan dipelajari dengan mengembangkan potensi akal yang dimiliki. Pengalaman menjadi perihal yang sangat penting dalam menggeneralisasi pendidikan. Karena dengannya, akal dapat tumbuh kembang sembari pengalaman yang telah dilalui manusia. Progresivisme pendidikan menjamin kebebasan berpikir manusia. Goals daripada pendidikan harus menyentuh ke depan. Menciptakan manusia yang kompetitif, kreatif, dan inovatif (Dewey, 1997a).

Joahn Dewey menjelaskan progresivisme pendidikan dapat ditempuh melalui organisasi pengalaman. Manusia dapat menggunakan pengalaman yang pernah dilalui sebagai bekal untuk mengembangkan pengalaman selanjutnya (Society \& Dewey, 1943). Hal demikian dapat dilakukan dengan dua cara. Pertama, meningkatkan esensi makna pengetahuan dan pengalaman yang terjadi secara simultan dan konsisten. Keduanya akan menjadi perihal penting dalam mengembangkan potensi akademik. Kedua, pengalaman menjadi alarm dan kontrol mandiri manusia dalam reaktualisasi pendidikan (Dewey, 1997b).

Unsur-unsur progresivisme pendidikan dapat diketahui melalui pengalaman, nilai, esensi pengetahuan, belajar, kurikulum, dan kebenaran (Tiles \& Tiles, 1992). Pengalaman sebagai perihal yang telah dilalui manusia, pengetahuan sebagai ilmu dan kontribusi akademik guna mengubah peradaban, belajar sebagai proses interaksi sosial antara guru dan murid, kurikulum sebagai komponen yang membantu proses belajar, dan kebenaran sebagai nilai-nilai yang dapat diadopsi (McDonald, 2012). Melalui pengalaman, manusia dapat mengembangkan potensi belajar dengan bantuan komponen kurikulum yang disediakan. Dari hasil belajar, manusia dapat menentukan nilainilai kebenaran untuk kebutuhan hidup ke depan.

\section{Manajemen Pendidikan Progresif dalam Konstelasi Filsafat}

Langkah progresivisme pendidikan yang dikemukakan John Dewey sebagaimana di atas telah memberi ruang gerak garapan dalam bidang pendidikan makro. Progresivisme pendidikan tidak serta 
merta berorientasi pada tujuan dan misi pembelajaran yang ditempuh setiap manusia, namun hakikatnya dapat menjumpai nilai dan esensi lebih dalam yang salah satunya adalah manajemen pendidikan.

Banyak teori yang menjelaskan manajemen pendidikan. Manajemen pendidikan dikatakan sebagai proses dalam sebuah pendidikan agar memiliki tujuan pendidikan yang dapat terukur dan tercapai. Di dalamnya terdapat sebuah proses perencanaan dan kontroling sumber daya manusia agar menghasilkan sesuatu yang efektif dan tepat guna. Manajemen pendidikan memiliki pola dan arah yang dirumuskan oleh seseorang dengan proses aktivitas sedemikian rupa dan mempertimbangkan sumber daya manusia yang tersedia (Wahyudin \& Permana, 2020).

Manajemen pendidikan ialah semua kegiatan sekolah dari yang meliputi usaha-usaha besar seperti pengarahan, koordinasi, konsultasi, korespondensi, kontrol perlengkapan, dan seterusnya hingga pada satuan unit terkecil (Wahyudin \& Permana, 2020). Manajemen pendidikan adalah seni dalam mengelola sumber daya pendidikan guna mewujudkan suasana belajar dan proses pembelajaran agar peserta didik secara aktif mengembangkan potensi dirinya untuk memiliki kekuatan spiritual, keagamaan, pengendalian diri, kepribadian, kecerdasan, akhlak mulia, serta keterampilan yang diperlukan dirinya, masyarakat, bangsa, dan negara (Gunawan \& Benty, 2017). Manajemen pendidikan dapat dikatakan sebagai ilmu terapan dalam bidang pendidikan yang merupakan rangkaian kegiatan atau keseluruhan proses pengendalian usaha kerja sama sejumlah orang untuk mencapai tujuan pendidikan yang dirumuskan secara sistematis. Tujuan pendidikan ini dapat dirumuskan oleh sekelompok masyarakat, individu, maupun lembaga pendidikan (Sudarmiani, n.d.).

Manajemen pendidikan dapat diartikan dengan aktivitas memadukan sumber-sumber pendidikan agara terpusat dalam usaha mencapai tujuan pendidikan yang telah ditentukan sebelumnya dengan mengarahkan orang-orang agar melaksanakan aktivitas tertentu untuk mencapai tujuan tertentu. Artinya, menggerakkan orang-orang untuk mengatur sarana, bahan, alat, biaya, serta dengan metode tertentu melakukan aktivitas mereka masing-masing (Sudarmiani, n.d.).

Uraian atas terminologi manajemen pendidikan di atas membuahkan pengertian bahwa tujuan pendidikan akan tercapai dengan sistemasi manajerial yang baik, mengoptimalkan sumber daya manusia, materi, dan sarana pendidikan yang tersedia. Pendidikan yang baik dapat terwujud dengan strategi dan metode yang dirumuskan matang-matang sebelumnya. Peneliti memberikan penjelasan secara rinci atas pemikiran John Dewey dalam manajemen pendidikan progresivisme.

Pertama, manusia dalam sistem manajemen pendidikan mempunyai kedudukan yang sangat sentral. Manusia sebagai agent of change dapat bekerjasama dengan sekelompok lain dalam 
mewujudkan nawa cita pendidikan. Dalam hal ini, Dewey menempatkan posisi manusia sebagai SDM yang memiliki peran penting dalam mengubah wajah pendidikan. Guna mewujudkan nawa cita pendidikan yang progresif, manusia sebagai SDM pendidikan dapat diorganisir dengan baik. Seperti diberikan peran dan tugas sesuai bakat minatnya. Dilatih dalam berkomunikasi dan kerjasama kelompok, serta diberdayakan dalam setiap kegiatan pendidikan. Ini adalah tugas daripada supervisior pendidikan. Di mana ia dapat mengorganisir manusia sebagai SDM yang aktif.

Kedua John Dewey mengamati betapa pendidikan harus berorientasi ke depan yang progresif. Hal ini dapat dicapai dengan manajemen pendidikan yang baik, semisal perumusan kurikulum pembelajaran yang berorientasi pada pengembangan akademik dan keterampilan siswa. Kurikulum yang dicanangkan memiliki nilai relevansi dengan kebutuhan masyarakat saat ini dan masa mendatang. Kurikulum bukanlah hal yang mutlak dan tidak bisa diubah. Kurikulum harus dinamis dan rekonstruktif menyesuaikan dengan kebutuhan zaman. Penataan kurikulum pendidikan demikian ialah salah satu unsur penting guna menuju pendidikan progresif. Kurikulum adalah jantung daripada pendidikan. Manajemen kurikulum yang matang dapat membentuk karakter pendidikan yang diharapkan. Saat ini telah banyak lembaga pendidikan yang berlomba-lomba dalam menentukan kualitas akademik. Lembaga-lembaga demikian tetap bernaungan kurikulum pendidikan dari Kementerian Pendidikan dan Kebudayaan RI, namun di dalamnya diselai materi-materi dan muatan lokal yang dibutuhkan secara simultan. Menyesuaikan kebutuhan pasar, geografi, dan keterampilan untuk daerah.

Ketiga, guna mencapai pendidikan progresif, John Dewey dalam pemikirannya menyebut sekolah sebagai miniatur masyarakat. Siswa yang dididik di sekolah kemudian dapat memberi kontribusi kepada masyarakat. Dalam hal ini, Dewey menyarankan sekolah tidak hanya berorientasi akademik, namun juga pendidikan moral dan psikologis. Sistem manajemen penataan lembaga pendidikan sekolah harus menjalin relasi dengan masyarakat. Sekolah tidak harus bersifat gradual, melainkan bersimbiosis dengan masyarakat. Diketahui saat ini banyak sekolah yang berorientasi pada potensi akademik siswa. Sehingga siswa kering dalam pendidikan moral apalagi psikologis. Akibatnya pada saat lulus, siswa cemerlang di bidang akademik tetapi tidak peka terhadap realitas sosial. Memiliki mental yang lemah karena tidak adanya penguatan unsur psikologis, bahkan memiliki perilaku destruktif karena krisis moral. Antara akademik, moral, dan psikologis menurut Dewey harus berjalan seimbang guna mewujudkan kesiapan siswa di tengah masyarakat. Dalam hal ini, lembaga pendidikan sekolah dapat merekonstruksi metode pendidikan untuk lebih baik dan memiliki orientasi simbiosis dengan masyarakat. 
Keempat, John Dewey memberikan ulasan bahwa manusia yang belajar memiliki ruang kebebasan akademik. Ia dapat belajar apapun yang diminati. Perlu dicatat dalam hal ini. John Dewey memberikan orientasi belajar pada aspek dinamis dan kreatif. Dalam arti apa yang dipelajari manusia secara empiris harus dapat mengembangkan potensi diri yang inovatif dan kreatif. Inovatif artinya setelah belajar, manusia dapat mengubah kreasi yang dikerjakannya dengan sedemikan rupa guna menjamin keberlangsungan hidup. Adapun kreatif artinya manusia dapat berkreasi terhadap bidang yang digelutinya setelah belajar. Tidak pakem dalam satu bidang, melainkan dapat berintegrasi dalam segala bidang guna mengembangkan potensi dan keterampilan diri. Dalam hal ini, lembaga pendidikan perlu menata manajemen perencanaan, kontrol, dan evaluasi. Lembaga pendidikan dalam kurikulumnya menentukan arah yang konkrit dan empiris atas tujuan pendidikan yang hendak dicapai. Dengan adanya rumusan tujuan pendidikan yang konkrit selanjutnya dilakukan sistem kontrol atas kegiatan belajar siswa. Hasil belajar dievaluasi sesuai dengan rumusan tujuan pendidikan yang ditentukan sebelumnya. Dengan demikian kebebasan akademik guna menciptakan manusia yang inovatif dan kreatif dapat terwujud.

\section{KESIMPULAN}

John Dewey sebagai filosof kontemporer banyak menuangkan gagasan dalam bidang pendidikan. Dalam pemikirannya, pendidikan harus berorientasi pada hal-hal yang sifatnya progresif, maju, dan berkembang. Pendidikan harus berorientasi pada kebutuhan diri dan masyarakat. Guna mewujudkan hal demikian, Dewey memberikan inferensi manajemen pendidikan. Manajemen pendidikan progresif menurutnya adalah sistem manajerial pendidikan yang mampu menggerakkan SDM, melakukan kontrol dan supervisi, serta mengevaluasi program kerja yang telah terlaksana. Filsafat progresivisme John Dewey merinci perihal tersebut sebagaimana berikut.

Pertama, manusia sebagai SDM pendidikan harus diberi peran dan tugas sesuai bakat dan minat yang digelutinya. Manusia adalah agent of change dalam pendidikan. Kedua, pendidikan memiliki orientasi ke depan dan progresif. Hal ini sebagai bentuk kritik atas sistem manajemen pendidikan skolastik. Pendidikan progresif dapat terwujud melalui rekonstruksi kurikulum yang progresif. Ketiga, lembaga pendidikan sekolah adalah miniatur kehidupan di masyarakat. Maka dengan hal tersebut sekolah perlu bersimbiosis dengan masyarakat guna mewujudkan tujuan pendidikan. Keempat, manusia yang belajar memiliki kebebasan akademik. Dalam arti manusia dapat belajar apapun sesuai yang diinginkan guna mengembangkan potensi dan keterampilan diri. 
Keempat hal demikian merupakan percikan pemikiran pendidikan progresif menurut John Dewey. Kemudian keempat hal demikian dapat terwujud melalui manajemen pendidikan yang progresif.

\section{DAFTAR PUSTAKA}

Arifin, N. (2021). Pemikiran Pendidikan John Dewey. As-Syar'i: Jurnal Bimbingan \& Konseling Keluarga, 2(2), 204-219. https://doi.org/10.47467/assyari.v2i2.128

Atabik, A., Wasliman, I., Sauri, S., \& Rostini, D. (2019). MANAJEMEN PENDIDIKAN KARAKTER DI SEKOLAH DALAM LINGKUNGAN PONDOK PESANTREN UNTUK MEMBINA AKHLAKUL KARIMAH. Nusantara Education Review, 2(3), 239-248.

Audi, R. (2015). The Cambridge Dictionary of Philosophy. Cambridge University Press. https://books.google.co.id/books?id=OfoNngEACAAJ

Dewey, J. (1997a). Democracy And Education. Free Press. https://books.google.co.id/books?id=OGIhNz4YJmkC

Dewey, J. (1997b). Experience And Education. Free Press. https://books.google.co.id/books?id=UWbuAAAAMAAJ

Dewey, J., Boydston, J. A., \& McDermott, J. J. (2008). The Later Works of John Dewey, 1925-1953: Essays, Reviews, Trotsky Inquiry, Miscellany, and Liberalism and Social Action. Southern Illinois University Press. https://books.google.co.id/books?id=pb0N4SgQGLQC

Faiz, A., \& Kurniawaty, I. (2020). Konsep Merdeka Belajar Pendidikan Indonesia Dalam Perspektif Filsafat Progresivisme. Konstruktivisme: Jurnal Pendidikan Dan Pembelajaran, 12(2), 155164

Gunawan, I., \& Benty, D. D. N. (2017). Manajemen Pendidikan: Suatu Pengantar Praktik.

Howlett, J. (2013). Progressive Education: A Critical Introduction. Bloomsbury Publishing. https://books.google.co.id/books?id=uXhvAAAAQBAJ

Islam, G. M. G. M. P. (n.d.). MANAJEMEN PENDIDIKAN DALAM PERSPEKTIF PROGRESIVISME DAN ISLAM.

Knight, G. R. (1998). Issues \& Alternatives in Educational Philosophy. Andrews University Press. https://books.google.co.id/books?id=htIlAQAAIAAJ

McDonald, H. P. (2012). John Dewey and Environmental Philosophy. State University of New York Press. https://books.google.co.id/books?id=OzUMrO4xwRMC 
Mualifah, I. (2016). PROGRESIVISME JOHN DEWEY DAN PENDIDIKAN PARTISIPATIF PERSPEKTIF PENDIDIKAN ISLAM. Jurnal Pendidikan Agama Islam (Journal of Islamic Education Studies), 1(1), 101. https://doi.org/10.15642/jpai.2013.1.1.101-121

Mulyasa, E. (2004). Manajemen berbasis sekolah: konsep, strategi dan implementasi.

Musyarapah, M. (2017). The Role of Progressive Philosophy in the Curriculum Based on John Dewey's Theory. Al-Hayat: Journal of Islamic Education, 1(1), 32-39.

Ruslan, R. (2018). Perspektif Aliran Filsafat Progresivisme Tentang Perkembangan Peserta Didik.

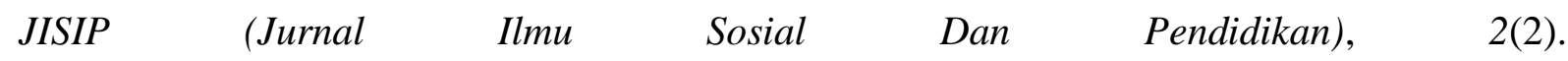
https://doi.org/http://dx.doi.org/10.36312/jisip.v2i2.372

Sirojudin, D., \& Ashoumi, H. (2020). Aksiologi Ilmu Pengetahuan Manajemen Pendidikan Islam. AlIdaroh: Jurnal Studi Manajemen Pendidikan Islam, 4(2), 182-195.

Society, J. D., \& Dewey, J. (1943). Yearbook of the John Dewey Society (Issue v. 6). D. AppletonCentury Company, Incorporated. https://books.google.co.id/books?id=BlvQHstyg_0C

Sudarmiani, B. (n.d.). MANAJEMEN PENDIDIKAN. Penerbit Andi. https://books.google.co.id/books?id=crZ-DwAAQBAJ

Tiles, J. E., \& Tiles, J. E. (1992). John Dewey. Routledge. https://books.google.co.id/books?id=M8bR2D6U9cEC

Wahyudin, U. R., \& Permana, H. (2020). Manajemen Pendidikan (Teori Dan Praktik Dalam Penyelenggaraan Sistem Pendidikan Nasional). Deepublish. https://books.google.co.id/books?id=qIv9DwAAQBAJ

Wikipedia, B. I. (2021). BiografI John Dewey. Wikipedia Bahasa Indonesia. https://id.wikipedia.org/wiki/John_Dewey

Wulandari, T. (2020). TEORI PROGRESIVISME JOHN DEWEY DAN PENDIDIKAN PARTISIPATIF DALAM PENDIDIKAN ISLAM. At-Tarbawi: Jurnal Kajian Kependidikan Islam, 5(1). https://doi.org/10.22515/attarbawi.v5i1.2221 